\title{
Untreated dental caries prevalence and impact on the quality of life among 11 to14-year-old Egyptian schoolchildren: a cross-sectional study
}

\author{
Samar Ahmed Eid ${ }^{1}$, Nagwa Mohmmad Ali Khattab² and Ahmad Abdel Hamid Elheeny ${ }^{2 *}$
}

\begin{abstract}
Background: This study aimed to assess caries prevalence and experience among 11 to 14 years, school children, analyze demographic, socioeconomic, personal and professional dental care in relation to untreated carious lesions, and evaluates the effect of decayed teeth on early adolescents' oral health-related quality of life (OHRQoL).

Methods: A cross-sectional analytical investigation was conducted on 1020 preparatory schoolchildren selected on the basis of a multistage sampling technique. Caries status of the participants detected via recording their caries experience and untreated cavities using DMFT and DT indices. OHRQOL was determined using a validated Arabic $\mathrm{CPQ}_{11-14}$ short-form questionnaire. Statistical methods for descriptive analysis, chi-square test, Independent-Samples $t$ test and one-way analysis of variance (ANOVA) were used. Multivariate Poisson regression analysis through a hierarchical approach was used to detect the influence of independent variables on DT scores. To declare the association between independent variables and QoL, a step-by-step, multivariate regression analysis was conducted.

Results: The average scores of DMFT and DT in this study were $2.97 \pm 1.29$ and $1.66 \pm 1.24$. Poisson regression analysis demonstrated that early adolescents whom their mothers with a lower level of education and of low socioeconomic status were 1.41 and 1.27 times respectively had higher DT scores when compared with their peers. Untreated cavities affected mainly by mother education, school type, family income, and regular dental appointments. Children with DMFT $\leq 3)$ or $\mathrm{DT}=0$ recorded a statistically significant lower $\mathrm{CPQ}_{11-14}$ average score $(p<0.01)$ and $(p<0.0001)$ respectively.

Conclusions: Untreated carious cavities and caries experience were associated with lower socioeconomic, maternal education andl ess frequent tooth brushing. Untreated carious cavities have a significant negative impact on schoolchildren's QoL.
\end{abstract}

Keywords: Adolescent, Oral health, Dental caries, quality of life

\footnotetext{
* Correspondence: ahmed.elheeny@nub.edu.eg

${ }^{2}$ Paediatric and Community Centistry, Faculty of Dentistry, Minia University,

Postal code, 61519. Province, Minya. Ard Shalaby, El Minia, Egypt

Full list of author information is available at the end of the article
}

(c) The Author(s). 2020 Open Access This article is licensed under a Creative Commons Attribution 4.0 International License, which permits use, sharing, adaptation, distribution and reproduction in any medium or format, as long as you give appropriate credit to the original author(s) and the source, provide a link to the Creative Commons licence, and indicate if changes were made. The images or other third party material in this article are included in the article's Creative Commons licence, unless indicated otherwise in a credit line to the material. If material is not included in the article's Creative Commons licence and your intended use is not permitted by statutory regulation or exceeds the permitted use, you will need to obtain permission directly from the copyright holder. To view a copy of this licence, visit http://creativecommons.org/licenses/by/4.0/. The Creative Commons Public Domain Dedication waiver (http://creativecommons.org/publicdomain/zero/1.0/) applies to the data made available in this article, unless otherwise stated in a credit line to the data. 


\section{Background}

Dental caries is one of the global health issues in both industrialized and developing communities. However, dental caries incidence and prevalence is more pronounced in developing countries like Egypt [1,2]. Dental caries is an age-related disease involving about $60-90 \%$ of schoolchildren [1,3]. Caries is an outcome of several interplaying factors such as cultural, social, and political factors, which in turn rule the individual behaviors and commitment to preventive oral hygiene measures [4]. Dental caries studying has raised attention in a critical life-stage like adolescence because caries progression increases at this stage [5]. In addition, at adolescence good oral hygiene, proper diet and regular dental check-up behaviors should be enforced. Untreated carious cavities especially when associated with pain may influence children's' physical and psychological development as well as school and daily-life achievements [6]. Plenty of studies revealed the association between oral health and adolescent's quality of life (QoL) physical, psychological, social and emotional aspects $[7,8]$. One of the tools designed by Jokovic et al. to measure the oral-health related quality of life (OHRQoL) in children is a child perception questionnaire for 11-14 years age group $\left(\mathrm{CPQ}_{11-14}\right)$ short form [9]. OHRQoL has a multidimensional structure to measure different aspects of oral health in a subjective way including oral symptoms, functional limitations, emotional and functional wellbeing [10]. Caries prevalence among Egyptian inhabitance is high [1]. The number of investigations conducted in Egypt especially among the early adolescents age group is limited. Moreover, up to the available data, the relation between decayed teeth and OHRQoL among teenagers Egyptian students is still not clarified.

The current study aimed to (1) assess caries prevalence and experience among 11 to14-year-old schoolchildren, (2) analyze demographic, socioeconomic, personal and professional dental care in relation to untreated carious lesions, (3) evaluate the effect of decayed teeth on early adolescent's OHRQoL.

\section{Methods}

\section{Design, setting and sampling}

A cross-sectional analytical study conducted in Minia City, Upper Egypt between September 2016 and April 2019. The needed number of children participating in the study was 927, which calculated on the basis of the following formula [11]; $\mathrm{N}=\left(\mathrm{Z}_{\alpha / 2}\right)^{2} \mathrm{~s}^{2} / \mathrm{d}^{2}$, where $(\mathrm{N})$ is the number of participants and (d) is the degree of precision adjusted at 0.05 (5\%), and the $\mathrm{Z}_{\alpha / 2}$ was $1.65 \mathrm{~A}$ pilot study conducted before launching the procedures on 56 children aged from 12 to 14 years and the standard deviation (s) of DMFT was 0.92 . The total sample size was
1020 children after adding $10 \%$ to compensate the dropoff. After obtaining the necessary permissions from the Ministry of Education, the sampling process has launched. The type of sample adopted in this study was a multistage stratified random sample. The selected strata based on gender (males and females), school type (public and private schools) and finally the school district (North, South, East or West). Details of sampling procedures illustrated in Fig. 1.

\section{Eligibility criteria}

Children aged from 11 to 14 years should fulfill the following criteria; (1) No orthodontic treatment or malocclusion or severe gingival or periodontal diseases. (2) Absence of any systemic, emotional or intellectual disabilities. (3) No emergency dental recall in the last 3 months.

\section{Study variables}

An anonymous questionnaire using a face-to-face interview has been adopted in this study. The questionnaire was divided into two principal sections; the first section included the following variables; (1) demographic data; (a) gender and (b) age, (2) socioeconomic data (a) mother's level of education; dichotomized according to the number of education years into $\geq 9$ years (greater than secondary and secondary school) and $<9$ years (less than secondary school or illiterate), (b) school type; classified into public and private schools, (c) household expenditures which recorded according to the cut-off poverty line in Egypt which is 3.20 US\$ per day and [12, 13], (3) dental self-care and use of dental services; (a) frequency of tooth brushing with fluoridated toothpaste, (b) frequency of fluoridated mouth rinse use. The response of both 'a' and 'b' dichotomized into regular use (frequency is $\geq 1$ time per day) and irregular (no tooth brushing or mouth wash use or $\leq 3$ times per week), (c) use of dental floss, (d) Do you regularly visit the dentist for regular check-up per year dichotomized into (yes or no). (4) clinical oral examination and recording dental caries status through recording the Decayed, Missing, Filled Teeth (DMFT) index for permanent teeth according to data into $(\leq 3$ and $>3$ ) based on the global target of score three announced by World Health Organization (WHO) for the year of 2000 [14]. Untreated carious cavity scores "i.e. Decayed tooth (DT) index" dichotomized into 0 and $\geq 1$. The second section concerned with evaluating the OHRQoL using a previously validated Arabic version of $\mathrm{CPQ}_{11-14}$ short-form consisted of 16 questions (four questions of each domain). The four domains assessed firstly, the oral symptoms (OS) included questions about pain in teeth/mouth, bad breath, mouth sore and food caught between teeth. The second domain 


*The number of students between 12 and 14
years in the Minia City (study target) $=$
55,979
Boys $=28,634$
Girls $=27,345$
*Total number preparatory schools in the
Minia City
Public $=18$
Private $=6$
*Schools are distributed on 6 districts

\begin{tabular}{|c|c|}
\hline \multicolumn{2}{|c|}{$\begin{array}{l}\text { Sampling procedure based on } \\
\text { district, gender and school type }\end{array}$} \\
\hline & $\begin{array}{l}\text { Two schools from each district (one for males and the } \\
\text { other for females) } \\
\text { Number of public schools }=12 \text { ( } 6 \text { for males and } 6 \text { for } \\
\text { females) } \\
\text { Number of private schools }=3 \text { (mixed schools) } \\
2 \text { schools from each district (one for males and the } \\
\text { other for females) } \\
\text { Total number of schools }=15 \text { schools }\end{array}$ \\
\hline
\end{tabular}

One class from each grade (3 classes per school) selected randomly

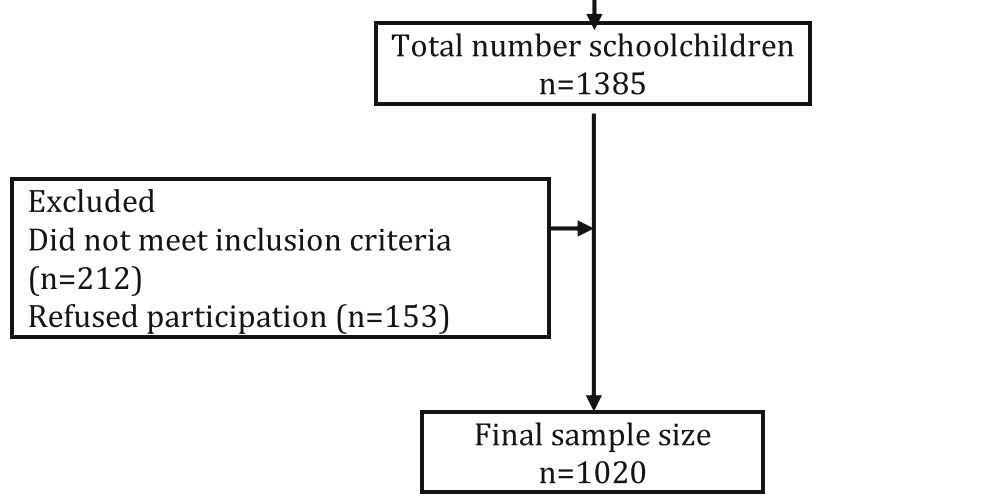

Fig. 1 Multistage sampling procedures

assessed the functional limitation (FL). For instance, the difficulty in chewing of firm food or saying words, sleeping problems and longer time has been taken to eat a meal. The third domain evaluated the emotional wellbeing $(\mathrm{EW})$ through questions concerned whether the participants felt upset, shy, frustrated or concerned what people think about his/her teeth. Finally, the social wellbeing (SW) domain illustrated through 4 questions (teased/called names, avoided smiling/laughing, argued with children/family and not wanted to speak/read loud in class). Response scores graduated on a 4-Likert point scale; (0) never, (1) once or twice, (2) sometimes, (3) often and (4) every day or almost every day. The minimum score was 0 and the maximum score was 64. Another one self-perception question reported by each participant about his/her OHRQoL evaluation $[9,15]$.

\section{Calibration, pilot study, and data collection}

Firstly, two dentists with at least 2 years of residency at the Pediatric and Dental Public Health Department, 
Faculty of Dentistry, Minia University, trained for 2 weeks for calibration. The second step was conducting a pilot study on 56 children. The pilot study aimed to determine QoL mean and standard deviation required for sample size calculation and to test the intraexaminer and inter-examiner reliability. The results of the pilot study did not include in the final statistical analysis. Dental caries examination performed at two appointments with one-week interval. The clinical examination carried out using a visual-tactile method using a dental mirror and WHO probe $5 \mathrm{~s}$ per dental surface under artificial light use [16].

\section{Statistical methods}

A Statistical Program Statistical Package for the Social Sciences (SPSS) version 20 has been used for statistical analysis. Data normality was examined and descriptive analysis including frequency tables, chi-square test for categorical variables, Independent-Samples $\mathrm{T}$-Test and one-way analysis of variance (ANOVA) to compare $\mathrm{CPQ}_{11-14}$ overall score means of independent predictors. The mean/standard deviation, and median/Interquartile range (IQR) of the $\mathrm{CPQ}_{11-14}$ different domains were calculated. Univariate Poisson regression analysis was performed to determine the associations between decayed teeth (i.e. outcome variable) and demographic, socioeconomic, dental care and oral health related quality of life self-perception independent predictors. Predictors with a significant level exceeding $0.2 \quad(\mathrm{p}>0.2)$ were excluded from the final adjusted multivariate regression model. A conceptual model was released according to a hierarchy approach of determinants and risk factors and it was structured according to the model made by Paula et al. as shown in Fig. 2 [17]. Predictors categorized into four models; Model 1 included gender, Model 2 incorporated model 1 plus socioeconomic variables Model 3 contained Model 2 plus child's dental care and Model 4 implicated model 3 plus child's oral health-related quality of life self-perception.

To declare the association between independent variables and QoL, a step-by-step, multivariate linear regression analysis was performed. The best fit defined by the highest $\left.\mathrm{R}^{2}\right)$. The level of significance was $5 \%(\mathrm{p}<0.05)$ and $95 \%$ confidence interval $(95 \% \mathrm{CI})$.

\section{Results}

Intra and inter-observer reliability; Kappa coefficients ( $\mathrm{k}$ ) were 0.91 and 0.86 for intra-examiner and interexaminer reliability respectively. More than two-thirds of participants are from the public. The prevalence of dental caries among school children $(\mathrm{DT} \geq 1)$ was $58.5 \%$. Approximately half of the participants showed caries experience exceeded scores three (DMFT $>3)$. The socioeconomic status displayed that more than two thirds of the participants' mothers had at least 9 years of education $(72.1 \%)$ and approximately one half the teenager's

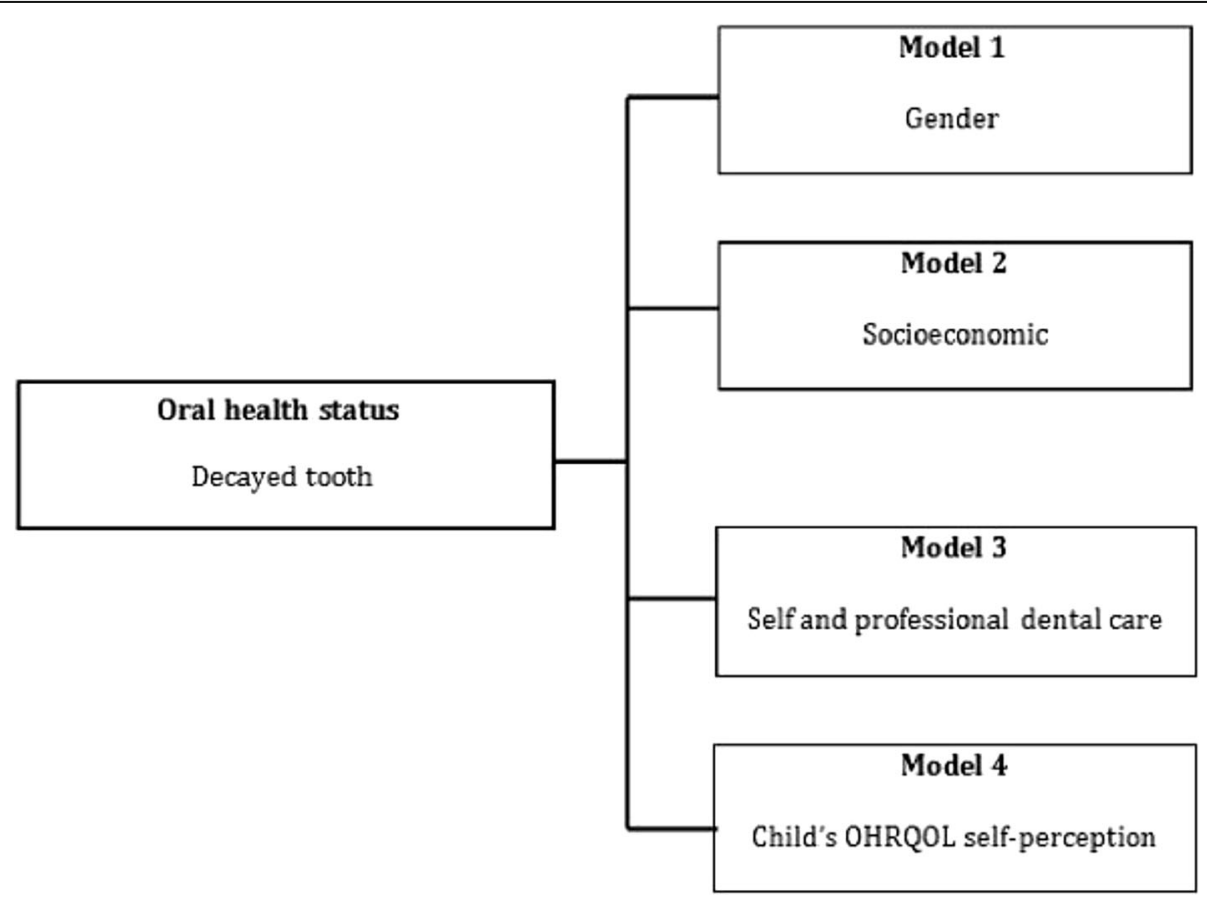

Fig. 2 Conceptual model of study variables 
Table 1 Frequency of demographic, socioeconomic, dental care, relation caries experience (DMFT) and decayed teeth (DT)

\begin{tabular}{|c|c|}
\hline Predictors & $N(\%)$ \\
\hline \multicolumn{2}{|l|}{ Gender } \\
\hline Male & $575(56.4)$ \\
\hline Female & $445(43.6)$ \\
\hline \multicolumn{2}{|l|}{ Age (years) } \\
\hline 12 & $323(31.6)$ \\
\hline 13 & 299(293) \\
\hline 14 & 398(39.1) \\
\hline \multicolumn{2}{|l|}{ School type } \\
\hline Public & $721(70.7)$ \\
\hline Private & 299(29.3) \\
\hline \multicolumn{2}{|c|}{ Mother education (years) } \\
\hline$\geq 9$ & $735(72.1)$ \\
\hline$<9$ & 285(27.9) \\
\hline \multicolumn{2}{|c|}{ Household expenditure } \\
\hline$>3.20 \$ /$ day & $547(53.6)$ \\
\hline$\leq 3.20 \$ /$ day & $473(46.4)$ \\
\hline \multicolumn{2}{|c|}{ Tooth brushing frequency } \\
\hline Irregular & 713(69.9) \\
\hline Regular & $307(30.1)$ \\
\hline \multicolumn{2}{|c|}{ Mouth washing frequency } \\
\hline Irregular & $865(84.8)$ \\
\hline Regular & 155(15.2) \\
\hline \multicolumn{2}{|c|}{ Dental appointment per year } \\
\hline No & $671(65.8)$ \\
\hline Yes & $349(34.2)$ \\
\hline \multicolumn{2}{|l|}{ Dental floss use } \\
\hline No & $887(87.0)$ \\
\hline Yes & 133(13.0) \\
\hline \multicolumn{2}{|l|}{ DMFT } \\
\hline$\leq 3$ & $513(50.3)$ \\
\hline$>3$ & $507(49.7)$ \\
\hline \multicolumn{2}{|l|}{ DT } \\
\hline 0 & $423(41.5)$ \\
\hline$\geq 1$ & $597(58.5)$ \\
\hline
\end{tabular}

family income was below the cut-off point of poverty (46.4\%). The majority of the teenagers did not use mouthwash or dental floss (84.8 and $87 \%$ respectively). Concerning toot brushing using a fluoridated tooth paste, only $30.1 \%$ of the participants were brushing their teeth on a regular basis (2 times daily) (Table 1 ).

The average scores of DMFT and DT in this study were $2.97 \pm 1.29$ and $1.66 \pm 1.24$. Caries experience showed no statistically significant difference between males and females. Maternal education, school type as an indicator of economic status, regular toothbrush and professional check-up revealed a significant impact on DMFT and DT scores $(\mathrm{p}<0.001)$ (Table 2).

Poisson regression analysis demonstrates that early adolescents whom their mothers with a lower level of education and of low socioeconomic status were 1.41 and 1.27 times respectively had higher DT scores when compared with their peers. Untreated cavities affected mainly by the mother education, school type, family income and regular dental appointments (Table 3).

Females report a higher score of $\mathrm{CPQ}_{11-14}$ means, indicating lower satisfaction with their OHRQoL than male counterparts $(p<0.0001)$. Regarding caries status, both caries experience $(\mathrm{DMFT} \leq 3)$ and decayed teeth score $(\mathrm{DT}=$ 0 ) record a statistically significant lower $\mathrm{CPQ}_{11-14}$ average scores $(\mathrm{p}<0.01)$ and $(\mathrm{p}<0.0001)$ respectively than those with higher DMFT and DT scores (Table 4).

OS domain especially, pain figures out the highest mean scores $(11.16 \pm 3.58)$ among $\mathrm{CPQ}_{11-14}$ different domains. FL, EW, and SW domains average scores are illustrated in Table 5.

Multiple regression analysis showed that untreated carious lesions (DT), socioeconomic status and constant toothbrush explain $64 \%$ of the variance in participant's QoL (Table 6).

\section{Discussion}

Dental caries have several negative impacts, especially on early adolescence life, through reducing the efficiency of masticatory function and general appearance which is reflected in growth and development as it affects emotional and social health. The current observational crosssectional study intended to assess the caries experience and its impact on OHRQL among a group of Egyptian school children aged from 11 to 14 years. This age group has been chosen to carry out this study based on the following aspects; (1) caries rate is higher among children [18], (2) this age group is the WHO target group for dental caries global comparison [14]. Data were gathered through a face-to-face interviews to eschew data missing, reduce information bias and enhance the accuracy of data [19]. The response rate was $87 \%$, this might be related to the use of anonymous $\mathrm{CPQ}_{11-14}$ questionnaire which also guarantees the participant's confidentiality.

Although the flood of data concerning the worldwide caries experience at various age groups, it still a significant issue to concern. Up to the available data, studies measuring caries experience among 11 to 14-year-old students were limited. Moreover, this work is a leading research in studying the association between caries and OHRQoL among early adolescent Egyptian students. The mean DMFT scores in this study were $2.97 \pm 1.29$ which approximately similar to the DMFT target 
Table 2 Frequency of demographic, socioeconomic, dental care, in relation caries experience (DMFT) and untreated decayed teeth (DT)

\begin{tabular}{|c|c|c|c|c|c|c|}
\hline \multirow[t]{2}{*}{ Predictors } & \multicolumn{2}{|l|}{ DT } & \multirow{2}{*}{$\begin{array}{l}p^{-} \\
\text {value }^{*}\end{array}$} & \multicolumn{2}{|l|}{ DMFT } & \multirow{2}{*}{$\underset{*}{p \text {-value }}$} \\
\hline & $\begin{array}{l}\mathrm{DT}=0 \\
\mathrm{~N}(\%)\end{array}$ & $\begin{array}{l}\mathrm{DT} \geq 1 \\
\mathrm{~N}(\%)\end{array}$ & & $\begin{array}{l}\mathrm{DMFT} \leq 3 \\
\mathrm{~N}(\%)\end{array}$ & $\begin{array}{l}\text { DMFT>3 } \\
N(\%)\end{array}$ & \\
\hline \multicolumn{7}{|l|}{ Gender } \\
\hline Male & 104(10.2) & $471(46.1)$ & $<0.0001$ & $326(32)$ & $249(24.4)$ & 0.53 \\
\hline Female & 187(18.3) & $258(25.3)$ & & $261(25.6)$ & 184(18) & \\
\hline \multicolumn{7}{|l|}{ Age (years) } \\
\hline 12 & 106(10.4) & $217(21.3)$ & 0.06 & 191(18.7) & $132(12.9)$ & 0.29 \\
\hline 13 & $88(8.6)$ & $211(20.7)$ & & $179(17.5)$ & $120(11.8)$ & \\
\hline 14 & $99(9.7)$ & 299(29.3) & & $217(21.3)$ & 181(17.7) & \\
\hline \multicolumn{7}{|l|}{ School type } \\
\hline Public & 136(13.3) & $585(57.4)$ & $<0.0001$ & 213(20.9) & $508(49.8)$ & 0.001 \\
\hline Private & 155(15.2) & $141(13.8)$ & & $179(17.5)$ & $120(11.8)$ & \\
\hline \multicolumn{7}{|c|}{ Mother education (years) } \\
\hline$\geq 9$ & $423(41.5)$ & $312(30.6)$ & $<0.0001$ & $513(50.3)$ & $182(17.8)$ & $<0.0001$ \\
\hline$<9$ & $85(8.3)$ & 200(19.6) & & $170(16.7)$ & 115(11.3) & \\
\hline \multicolumn{7}{|c|}{ Household expenditure } \\
\hline$>3.20 \$ /$ day & $255(25)$ & 292(28.6) & 0.01 & $323(31.7)$ & $224(22)$ & 0.29 \\
\hline$\leq 3.20 \$ /$ day & 134(13.1) & $339(33.2)$ & & 264(25.9) & $209(20.5)$ & \\
\hline \multicolumn{7}{|c|}{ Tooth brushing frequency } \\
\hline Irregular & $125(12.3)$ & $588(57.6)$ & $<0.0001$ & $330(32.4)$ & $383(37.5)$ & $<0.0001$ \\
\hline Regular & $176(17.3)$ & 131(12.8) & & $204(20)$ & 103(10.1) & \\
\hline \multicolumn{7}{|c|}{ Mouth washing frequency } \\
\hline Irregular & $268(26.3)$ & $686(67.3)$ & 0.24 & $358(35.1)$ & $507(49.7)$ & 0.34 \\
\hline Regular & $23(2.3)$ & $43(4.2)$ & & $93(9.1)$ & $62(6.1)$ & \\
\hline \multicolumn{7}{|c|}{ Dental appointment per year } \\
\hline No & 136(13.3) & $535(52.5)$ & $<0.0001$ & $267(26.2)$ & 404(39.6) & $<0.0001$ \\
\hline Yes & 196(19.2) & $153(15)$ & & $214(20.1)$ & 135(13.2) & \\
\hline \multicolumn{7}{|l|}{ Dental floss use } \\
\hline No & $260(28.4)$ & $597(58.5)$ & 0.07 & $372(36.5)$ & $515(50.5)$ & 0.39 \\
\hline Yes & $30(2.9)$ & 103(10.1) & & $72(7.1)$ & $61(5.9)$ & \\
\hline
\end{tabular}

${ }^{*}$ Chi-square test

declared by the World Health Organization (WHO) in 2000 [14]. Untreated cavities mean values were higher among girls than boys. This difference might be attributed to the higher commitment of girls toward oral hygiene habits like tooth brushing than boys. This finding was in agreement with prior studies [1,20]. The River Nile is the main source of water in the Egypt. The fluoride contents of Nile waters fluctuate between 0.2 and $0.4 \mathrm{mg}-\mathrm{F} / \mathrm{L}$ of average of $0.34 \mathrm{mg}-\mathrm{F} / \mathrm{L}$. As Minia located in the Upper Egypt where the weather is hot over the year and subsequently the water consumption increases. In addition, the habits of drinking tea and the use of water in cooking are common. Therefore, the final consumption of water which come from the River Nile is approximately $0.7 \mathrm{mg}-\mathrm{F} / \mathrm{L}$ which compatible with the optimum level of Fluoride announced by The WHO which ranged from 0.7 to $1.2 \mathrm{mg}-\mathrm{F} / \mathrm{L}$ [21]. Despite of water fluoridation in Egypt provides the optimum level of fluoride, caries prevalence in the current study was high and this might be related to the complex nature of the disease which requires a multidisciplinary approach for its prevention.

In the present study, caries experience was higher than that reported by two former studies conducted in a nearly similar Egyptian age group. The first study performed in 2011, on 976 schoolchildren [2]. The average DMFT score was $1.68 \pm 1.92$, and this might be assigned to the use of a distinct sampling method which relied on 
Table 3 Poisson analysis for decayed teeth (DT) in relation to demographic, socioeconomic and dental care

\begin{tabular}{|c|c|c|c|c|c|c|c|c|c|c|}
\hline \multirow[t]{2}{*}{ Predictors } & \multicolumn{2}{|l|}{ Univariate analysis } & \multicolumn{2}{|l|}{ Model 1} & \multicolumn{2}{|l|}{ Model 2} & \multicolumn{2}{|l|}{ Model 3} & \multicolumn{2}{|l|}{ Model 4} \\
\hline & Unadjusted PR 95\% Cl & $p$-value & $\begin{array}{l}\text { Adjusted PR } \\
95 \% \mathrm{Cl}\end{array}$ & $p$-value & $\begin{array}{l}\text { Adjusted PR } \\
95 \% \mathrm{Cl}\end{array}$ & $p$-value & $\begin{array}{l}\text { Adjusted PR } \\
95 \% \mathrm{Cl}\end{array}$ & $p$-value & $\begin{array}{l}\text { Adjusted PR } \\
95 \% \mathrm{Cl}\end{array}$ & $p$-value \\
\hline \multicolumn{11}{|l|}{ Gender } \\
\hline Male & $1.07(0.98 ; 1.14)$ & 0.17 & $0.94(0.80 ; 1.11)$ & 0.47 & $1.07(0.86 ; 1.18)$ & 0.11 & $0.99(0.84 ; 1.16)$ & 0.90 & $1.06(0.98 ; 1.14)$ & 0.15 \\
\hline Female & 1 & & 1 & & 1 & & 1 & & 1 & \\
\hline \multicolumn{11}{|c|}{ Mother education (years) } \\
\hline$<9$ & $1.21(1.06 ; 1.24)$ & 0.002 & & & $1.58(1.27 ; 1.95)$ & $<0.0001$ & $1.56(1.25 ; 1.95)$ & $<0.0001$ & $1.41(1.14 ; 1.74)$ & 0.006 \\
\hline$\geq 9$ & 1 & & & & 1 & & 1 & & 1 & \\
\hline \multicolumn{11}{|l|}{ School type } \\
\hline Public & $1.14(1.09 ; 1.29)$ & 0.01 & & & $1.34(1.09 ; 1.64)$ & 0.006 & $1.48(1.18 ; 1.85)$ & 0.001 & $1.27(1.17 ; 1.38)$ & 0.02 \\
\hline Private & 1 & & & & 1 & & 1 & & 1 & \\
\hline \multicolumn{11}{|c|}{ Household expenditure } \\
\hline$<3.20 \$ /$ day & $1.16(1.06 ; 3.19)$ & 0.02 & & & $1.21(1.03 ; 1.33)$ & 0.018 & $1.23(1.11 ; 1.39)$ & 0.01 & $1.22(1.12 ; 1.49)$ & 0.04 \\
\hline$\geq 3.20 \$$ /day & 1 & & & & 1 & & 1 & & 1 & \\
\hline \multicolumn{11}{|l|}{ Tooth brushing } \\
\hline Irregular & $1.21(1.06 ; 1.49)$ & 0.05 & & & & & $1.02(0.75 ; 1.15)$ & 0.51 & $1.14(0.80 ; 1.84)$ & 0.46 \\
\hline Regular & 1 & & & & & & 1 & & 1 & \\
\hline \multicolumn{11}{|c|}{ Dental appointments } \\
\hline No & $1.11(1.05 ; 1.23)$ & 0.03 & & & & & $1.20(1.04 ; 1.29)$ & 0.04 & $1.25(1.16 ; 1.46)$ & 0.004 \\
\hline Yes & 1 & & & & & & 1 & & 1 & \\
\hline \multicolumn{11}{|l|}{ Mouth wash use } \\
\hline No & $1.03(0.79 ; 1.33)$ & 0.85 & & & & & $1.08(0.89 ; 1.94)$ & 0.14 & $1.18(0.89 ; 1.84)$ & 0.19 \\
\hline Yes & 1 & & & & & & 1 & & 1 & \\
\hline \multicolumn{11}{|l|}{ Dental floss use } \\
\hline No & $1.07(0.70 ; 1.22)$ & 0.30 & & & & & $1.12(0.91 ; 1.28)$ & 0.48 & $1.05(0.8 ; 1.36)$ & 0.73 \\
\hline Yes & 1 & & & & & & 1 & & 1 & \\
\hline
\end{tabular}

$P R$ Prevalence Ratio

choosing only two public schools (one for boys and the other for girls) from the Giza governorate. In addition, school enrollment of children in Egypt depends fundamentally on geographic distribution. Therefore, the approach might consider children who nearly have similar socioeconomic and parents' educational backgrounds. The DMFT score of the other study published in 2019, was also lesser than the results of the current study $(1.68 \pm 1.92)$ [1]. The reason might be due to the difference between the two studies in sample size. Caries prevalence of untreated carious cavities in the present study was $58.5 \%$ which was higher than that reported by a Pontigo-loyola et al. who reported a caries prevalence of $48.6 \%$ among 12 and 15 age children in high altitudes [22]. The difference might be related to the higher community water fluoridation which surpassed the systemic water fluoridation in Egypt. The findings of skinner et al. published a caries prevalence of $45 \%$ among 14 and 15year-olds in New South Wales, Australia [23]. In comparison, global DMFT scores reported in other countries showed a wide range of diversity. Some researches revealed lower DMFT scores than the finding of the current research [24-28]. Other research reported nearly similar results [29-31]. While a number of researches recorded higher DMFT scores [14, 32, 33]. This wide range of diversity attributed to the differences in study designs, sample sizes, eating habits and socioeconomic and cultural backgrounds. In the current study, children with lower DMFT and DT scores were belonging to families with higher income as well as education level in comparison to children with high caries experience. This inverse relationship between DMFT scores and both maternal education level and economic status denotes their significant impact on caries experience. Several previous studies confirmed this relationship [34-36]. Lower socioeconomic status might hinder the adherence to preventive interventions such as tooth brushing and regular professional dental examination which consistent with other studies. Moreover, these associations were also evident with untreated carious cavities [37]. 
Table 4 Mean of Decayed, Missed, Filled (DMFT) index and decayed teeth (DT) scores in relation to demographic, socioeconomic, dental care, relation

\begin{tabular}{|c|c|c|}
\hline Predictors & $\mathrm{CPQ}_{11-14}$ Mean (SD) scores & $p$-value * \\
\hline \multicolumn{3}{|l|}{ Gender } \\
\hline Male & $38.07(12.60)$ & \multirow[t]{2}{*}{$<0.0001$} \\
\hline Female & $42.20(10.49)$ & \\
\hline \multicolumn{3}{|l|}{ Age (years) } \\
\hline 12 & 40.96(12.14) & \multirow[t]{3}{*}{0.13} \\
\hline 13 & $42.82(9.64)$ & \\
\hline 14 & $41.32(12.66)$ & \\
\hline \multicolumn{3}{|l|}{ School type } \\
\hline Public & $44.64(8.28)$ & \multirow[t]{2}{*}{$<0.0001$} \\
\hline Private & $30.16(12.18)$ & \\
\hline \multicolumn{3}{|c|}{ Mother education (years) } \\
\hline$\geq 9$ & $40.46(11.67)$ & \multirow[t]{2}{*}{0.014} \\
\hline$<9$ & $38.13(11.50)$ & \\
\hline \multicolumn{3}{|c|}{ Household expenditure } \\
\hline$>3.20 \$ /$ day & $36.36(13.26)$ & \multirow[t]{2}{*}{$<0.0001$} \\
\hline$\leq 3.20 \$ /$ day & $45.06(6.94)$ & \\
\hline \multicolumn{3}{|c|}{ Tooth brushing frequency } \\
\hline Irregular & $41.73(11)$ & \multirow[t]{2}{*}{$<0.0001$} \\
\hline Regular & $35.33(12.56)$ & \\
\hline \multicolumn{3}{|c|}{ Mouth washing frequency } \\
\hline Irregular & 40.79(11.46) & \multirow[t]{2}{*}{$<0.0001$} \\
\hline Regular & $34.77(12.68)$ & \\
\hline \multicolumn{3}{|c|}{ Dental appointment per year } \\
\hline No & $43.40(9.41)$ & \multirow[t]{2}{*}{$<0.0001$} \\
\hline Yes & $34.67(13.23)$ & \\
\hline \multicolumn{3}{|l|}{ Dental floss use } \\
\hline No & $40.65(11.55)$ & \multirow[t]{2}{*}{0.076} \\
\hline Yes & $38.73(12.10)$ & \\
\hline \multicolumn{3}{|l|}{ DMFT } \\
\hline$\leq 3$ & $34.05(12.46)$ & \multirow[t]{2}{*}{0.002} \\
\hline$>3$ & $42.22(10.14)$ & \\
\hline \multicolumn{3}{|l|}{ DT } \\
\hline 0 & $27.66(12.76)$ & \multirow[t]{2}{*}{$<0.0001$} \\
\hline$\geq 1$ & $45.48(5.81)$ & \\
\hline
\end{tabular}

Dental caries has a negative impact on the adolescent's QoL. The present study utilized $\mathrm{CPQ}_{11-14}$ short form which reported by Jokovic et al. to have excellent validity and maintained its multidimensional properties [9]. Direct comparison between the results of this study and the findings of global researches concerned with the impact of caries on OHRQoL might be influenced with the diversity of socioeconomic, traditions and cultural backgrounds. However, it was salutary to consider some of these studies. In the present, oral symptoms especially pain demonstrated the highest mean scores which demonstrated the prominent influence on eating, speaking and sleeping aspects. These were in agreement with the findings of former studies [38, 39]. Untreated carious lesions can lead to what could be called a "vicious cycle" because pain or teeth loss as a result of the carious tooth will reduce the mastication performance due to the difficulty in hard food chewing and subsequently, a shift toward more soft and processed food will take place. This food usually more cariogenic and of little nutritional benefits which will increase the caries progression and subsequent increase in more soft food consumption. Another negative aspect of soft and highly processed foods is their passive effect on children's growth and development $[40,41]$. Unfortunately, oral symptoms not the only consequences of pain or missing teeth due to decay in this study, but also, the emotional effect on the participants in this study was announced. This can be explained by the undermining of children's self-esteem due to altered eating, chewing, speaking and social appearance $[41,42]$. The current study emphasized the connection between low socioeconomic status and OHRQoL. The education level of mothers and financial status plays a vital role in an individual's lifestyle decisions and adherence to routine preventive measures such as tooth brushing and get access to dental services.

The findings of this study spotlight the importance of adopting strategies aimed to increase awareness about oral health among mothers and school children at this age and emphasize the importance of oral hygiene habits. It is also recommended to reduce socioeconomic inequalities.

*Independent-Sample T test; One Way (ANOVA)

Table 5 Perceived oral health related quality of life (OHRQoL) based on the scores of child perception questionnaire $C P Q_{11-14}$ domains

\begin{tabular}{llll}
\hline $\mathrm{CPQ}_{11-14}$ domains & Mean (SD) & Median (IQR) & Cronbach's alpha \\
\hline Oral symptoms (OS) & $11.16 \pm 3.58$ & $12(4.75)$ & 0.71 \\
Functional limitations (FL) & $10.45 \pm 3.25$ & $11(5)$ & 0.67 \\
Emotional well-being (EW) & $10.15 \pm 3.42$ & $11(5)$ & 0.61 \\
Social well-being (SW) & $9.75 \pm 2.98$ & $10(3)$ & 0.67 \\
Overall score & $42.40 \pm 11.63$ & $43(11.75)$ & 0.84 \\
\hline
\end{tabular}


Table 6 Multiple regression analysis of factors influencing oral health related quality of life (OHRQoL) in 11 to 14 years school children

\begin{tabular}{|c|c|c|c|c|}
\hline Predictors & $\beta$ & $95 \% \mathrm{Cl}$ & $p$-value & Adjusted $R^{2}$ \\
\hline \multicolumn{5}{|l|}{ Step 1} \\
\hline Gender & 0.18 & $2.75 ; 5.58$ & $<0.0001$ & \multirow[t]{2}{*}{0.04} \\
\hline Age (years) & -0.83 & $-1.67 ;-0.26$ & 0.007 & \\
\hline \multicolumn{5}{|l|}{ Step 2} \\
\hline Gender & 0.08 & $0.68 ; 2.98$ & 0.002 & \multirow[t]{5}{*}{0.38} \\
\hline Age (years) & -0.02 & $-0.82 ; 0.31$ & 0.38 & \\
\hline Household expenditure & 0.16 & $2.30 ; 5.01$ & $<0.0001$ & \\
\hline School type & -0.54 & $-15.34 ;-12.38$ & $<0.0001$ & \\
\hline Mother education & -0.23 & $-8.42 ;-5.30$ & $<0.0001$ & \\
\hline \multicolumn{5}{|l|}{ Step 3} \\
\hline Gender & 0.08 & $075 ; 3.05$ & 0.001 & \multirow[t]{9}{*}{0.4} \\
\hline Age (years) & -0.2 & $-0.79 ; 0.33$ & 0.43 & \\
\hline Household expenditure & 0.14 & $1.99 ; 4.67$ & $<0.0001$ & \\
\hline School type & -0.5 & $-14.26 ;-11.04$ & $<0.0001$ & \\
\hline Mother education & -0.22 & $-8.18 ;-5.04$ & $<0.0001$ & \\
\hline Mouth washing frequency & -0.05 & $-5.24 ; 0.16$ & 0.07 & \\
\hline Tooth brushing frequency & -0.11 & $-1.59 ; 0.56$ & $<0.0001$ & \\
\hline Dental appointment & -0.07 & $-3.15 ;-0.21$ & 0.025 & \\
\hline Dental floss use & -0.07 & $-2.21 ;-0.17$ & 0.014 & \\
\hline \multicolumn{5}{|l|}{ Step 4} \\
\hline Gender & -0.03 & $-1.54 ; 0.28$ & 0.17 & \multirow[t]{11}{*}{0.64} \\
\hline Age (years) & -0.03 & $-0.77 ; 0.09$ & 0.12 & \\
\hline Household expenditure & 0.07 & $0.62 ; 2.70$ & 0.002 & \\
\hline School type & -0.38 & $-10.97 ;-8.45$ & $<0.0001$ & \\
\hline Mother education & -0.17 & $-6.36 ;-3.93$ & $<0.0001$ & \\
\hline Mouth washing frequency & -0.04 & $-3.89 ; 0.28$ & 0.09 & \\
\hline Tooth brushing frequency & -0.07 & $-1.05 ;-0.26$ & 0.001 & \\
\hline Dental appointment & -0.08 & $-1.58 ; 0.73$ & 0.47 & \\
\hline Dental floss use & -0.05 & $-1.53 ; 1.44$ & 0.95 & \\
\hline DMFT & 0.02 & $-0.34 ; 1.45$ & 0.23 & \\
\hline DT & 0.54 & $12.88 ; 15.03$ & $<0.0001$ & \\
\hline
\end{tabular}

The present study has a number of strong features such as the representative sample, high response rate as well as intra-examiner and inter-examiner reliability. All of these points are positively reflected in the study generalization as well as its internal validity. On the other hand, the main weak point in this study was attributed to the cross-sectional design as data collected at one point of time in contrast to the prospective design.

\section{Conclusions}

The present study clarifies that more than half of schoolchildren aged from 11 to 14-years showed untreated cavities. This may declare the negative impact of untreated carious lesions and negative QoL. However, caries experience recorded no significant alliance with OHRQoL. Both untreated cavities and caries experience were significantly associated with lower household expenditure, lower maternal education and irregular adherence to tooth brushing habit. Oral symptoms were the chief domains that adversely influencing early adolescent's OHRQoL. Further studies especially the longitudinal study are required to assess the correlation between these different variables and OHRQoL different aspects.

\section{Abbreviations}

QoL: Quality of Life; OHRQoL: Oral-Health Related Quality of Life; $C_{1} Q_{11-}$ 14: Child Perception Questionnaire for 11-14 years; DMFT: Decayed, Missing, 
Filled Teeth; WHO: World Health Organization; DT: Decayed Tooth; OS: Oral Symptoms; FL: Functional limitation; EW: Emotional well-being; SW: Social Well-being

\section{Acknowledgments}

The author is deeply appreciated to all participants and their parents for their full cooperation to conduct this work. In addition, I would like to thank the Paediatric residents AMM and EKM in Paediatric Dentistry Department for their crucial contribution to oral examination and data recording. In addition, the author appreciates all the staff members and the nursing staff at the Paediatric Dentistry Department, Faculty of Dentistry, Minia University for their help and care of our precious children.

\section{Authors' contributions}

Author EAA was responsible for the research idea, paper writing and formatting and statistical analysis. Author ES was responsible for the clinical aspects of the study and data gathering. Author KN was responsible for revising the work. The author(s) read and approved the final manuscript.

\section{Funding}

The search was self-funded and no other sources for funding for the research.

\section{Availability of data and materials}

The datasets used and/or analysed during the current study are available from the corresponding author on reasonable request.

\section{Ethics approval and consent to participate}

This study reviewed and signed by the Ethics Committee of Faculty of Dentistry, Minia University (registration number 174/2015). The current study conducted in full accordance with the World Medical Association Declaration of Helsinki. All participants or their legal guardians signed the informed consent form before participating in any part of the research.

\section{Consent for publication}

Not applicable.

\section{Competing interests}

The authors declare that they have no competing interests.

\section{Author details}

${ }^{1}$ Ministry of Health, Fayum, Egypt. ${ }^{2}$ Paediatric and Community Centistry, Faculty of Dentistry, Minia University, Postal code, 61519. Province, Minya. Ard Shalaby, El Minia, Egypt.

\section{Received: 15 November 2019 Accepted: 12 March 2020}

Published online: 19 March 2020

\section{References}

1. Abbass MMS, Mahmoud SA, El Moshy S, Rady D, AbuBakr N, Radwan IA, Ahmed A, Abdou A, Al Jawaldeh A. The prevalence of dental caries among Egyptian children and adolescences and its association with age, socioeconomic status, dietary habits and other risk factors. A cross-sectional study. F1000Res. 2019;8:8.

2. Mobarak EH, Shabayek MM, Mulder J, Reda AH, Frencken JE. Caries experience of Egyptian adolescents: does the atraumatic restorative treatment approach offer a solution? Med Princ Pract. 2011;20(6):545-9.

3. Petersen PE. The burden of oral disease: challenges to improving oral health in the 21st century. Bull World Health Organ. 2005;83(1):3.

4. Ortiz AS, Tomazoni F, Knorst JK, Ardenghi TM. Influence of socioeconomic inequalities on levels of dental caries in adolescents: a cohort study. Int J Paediatr Dent. 2020;30(1):42-9.

5. Merdad L, El-Housseiny AA. Do children's previous dental experience and fear affect their perceived oral health-related quality of life (OHRQoL)? BMC Oral Health. 2017;17(1):47.

6. Mota-Veloso I, Soares ME, Alencar BM, Marques LS, Ramos-Jorge ML, RamosJorge J. Impact of untreated dental caries and its clinical consequences on the oral health-related quality of life of schoolchildren aged 8-10 years. Qual Life Res. 2016;25(1):193-9.

7. Akesson ML, Warnberg Gerdin E, Soderstrom U, Lindahl B, Johansson I. Health-related quality of life and prospective caries development. BMC Oral Health. 2016;16:15.
8. Kastenbom L, Falsen A, Larsson P, Sunnegardh-Gronberg K, Davidson T. Costs and health-related quality of life in relation to caries. BMC Oral Health. 2019;19(1):187.

9. Jokovic A, Locker D, Guyatt G. Short forms of the child perceptions questionnaire for 11-14-year-old children (CPQ11-14): development and initial evaluation. Health Qual Life Outcomes. 2006;4:4.

10. Sischo L, Broder HL. Oral health-related quality of life: what, why, how, and future implications. J Dent Res. 2011;90(11):1264-70.

11. Suresh K, Chandrashekara S. Sample size estimation and power analysis for clinical research studies. J Hum Reprod Sci. 2012;5(1):7-13.

12. Fosu AK. Inequality, income, and poverty: comparative global evidence. Soc Sci Q. 2010;91(5):1432-46.

13. Mowafi M, Khadr Z, Kawachi I, Subramanian SV, Hill A, Bennett GG. Socioeconomic status and obesity in Cairo, Egypt: a heavy burden for all. J Epidemiol Glob Health. 2014;4(1):13-21.

14. Al-Darwish M, El Ansari W, Bener A. Prevalence of dental caries among 1214 year old children in Qatar. Saudi Dent J. 2014;26(3):115-25.

15. Brown A, Al-Khayal Z. Validity and reliability of the Arabic translation of the child oral-health-related quality of life questionnaire (CPQ11-14) in Saudi Arabia. Int J Paediatr Dent. 2006;16(6):405-11.

16. Assaf AV, Meneghim Mde C, Zanin L, Mialhe FL, Pereira AC, Ambrosano GM. Assessment of different methods for diagnosing dental caries in epidemiological surveys. Community Dent Oral Epidemiol. 2004;32(6):418-25.

17. Paula JS, Ambrosano GM, Mialhe FL. The impact of social determinants on schoolchildren's oral health in Brazil. Braz Oral Res. 2015;29:1-9.

18. Clinical Affairs Committee AAoPD. Guideline on adolescent Oral health care. Pediatr Dent. 2015;37(5):49-56.

19. Khattab NMA, Elheeny AAH, Tony GA. Oral-cancer knowledge, practice, and attitude assessment of dentists in upper Egypt: a cross-sectional study. Clin Exp Dent Res. 2019:5(2):121-7.

20. Mamai-Homata E, Koletsi-Kounari H, Margaritis V. Gender differences in oral health status and behavior of Greek dental students: a meta-analysis of 1981, 2000, and 2010 data. J Int Soc Prev Community Dent. 2016;6(1):60-8.

21. Emslie RD. A dental health survey in the Republic of the Sudan. Br Dent J. 1966;120(4):167-78.

22. Pontigo-Loyola AP, Medina-Solis CE, Borges-Yanez SA, Patino-Marin N, IslasMarquez A, Maupome G. Prevalence and severity of dental caries in adolescents aged 12 and 15 living in communities with various fluoride concentrations. J Public Health Dent. 2007;67(1):8-13.

23. Skinner J, Johnson G, Phelan C, Blinkhorn A. Dental caries in 14- and 15year-olds in New South Wales, Australia. BMC Public Health. 2013;13:1060.

24. Christian B, Ummer-Christian R, Blinkhorn A, Hegde V, Nandakumar K, Marino R, Chattopadhyay A. An epidemiological study of dental caries and associated factors among children residing in orphanages in Kerala, India: health in orphanages project (HOPe). Int Dent J. 2019;69(2):113-8.

25. Nurelhuda NM, Trovik TA, Ali RW, Ahmed MF. Oral health status of 12-yearold school children in Khartoum state, the Sudan; a school-based survey. BMC Oral Health. 2009;9:15

26. Ahmed NA, Astrom AN, Skaug N, Petersen PE. Dental caries prevalence and risk factors among 12-year old schoolchildren from Baghdad, Iraq: a postwar survey. Int Dent J. 2007:57(1):36-44.

27. Masood M, Yusof N, Hassan Ml, Jaafar N. Longitudinal study of dental caries increment in Malaysian school children: a 5-year cohort study. Asia Pac J Public Health. 2014;26(3):260-7.

28. Campus G, Cagetti MG, Senna A, Sacco G, Strohmenger L, Petersen PE. Caries prevalence and need for dental care in 13-18-year-olds in the municipality of Milan, Italy. Community Dent Health. 2008;25(4):237-42.

29. Jamelli SR, Rodrigues CS, de Lira PI. Nutritional status and prevalence of dental caries among 12-year-old children at public schools: a case-control study. Oral Health Prev Dent. 2010;8(1):77-84.

30. Pakpour AH, Hidarnia A, Hajizadeh E, Kumar S, Harrison AP. The status of dental caries and related factors in a sample of Iranian adolescents. Med Oral Patol Oral Cir Bucal. 2011;16(6):e822-7.

31. Al-Mutawa SA, Shyama M, Al-Duwairi Y, Soparkar P. Dental caries experience of Kuwaiti schoolchildren. Community Dent Health. 2006;23(1):31-6.

32. Delgado-Angulo EK, Hobdell MH, Bernabe E. Poverty, social exclusion and dental caries of 12-year-old children: a cross-sectional study in Lima, Peru. BMC Oral Health. 2009;9:16

33. Hysi D, Caglar E, Droboniku E, Toti C, Kuscu OO. Dental caries experience among Albanian pre-school children: a national survey. Community Dent Health. 2017;34(1):46-9. 
34. Oliveira LB, Sheiham A, Bonecker M. Exploring the association of dental caries with social factors and nutritional status in Brazilian preschool children. Eur J Oral Sci. 2008;116(1):37-43.

35. Pattussi MP, Marcenes W, Croucher R, Sheiham A. Social deprivation, income inequality, social cohesion and dental caries in Brazilian school children. Soc Sci Med. 2001;53(7):915-25.

36. Piovesan C, Mendes FM, Antunes JL, Ardenghi TM. Inequalities in the distribution of dental caries among 12-year-old Brazilian schoolchildren. Braz Oral Res. 2011;25(1):69-75.

37. Polk DE, Weyant RJ, Manz MC. Socioeconomic factors in adolescents' oral health: are they mediated by oral hygiene behaviors or preventive interventions? Community Dent Oral Epidemiol. 2010;38(1):1-9.

38. Bastos RS, Carvalho ES, Xavier A, Caldana ML, Bastos JR, Lauris JR. Dental caries related to quality of life in two Brazilian adolescent groups: a crosssectional randomised study. Int Dent J. 2012;62(3):137-43.

39. Jurgensen N, Petersen PE. Oral health and the impact of socio-behavioural factors in a cross sectional survey of 12-year old school children in Laos. BMC Oral Health. 2009;9:29.

40. Lima SLA, Santana CCP, Paschoal MAB, Paiva SM, Ferreira MC. Impact of untreated dental caries on the quality of life of Brazilian children: population-based study. Int J Paediatr Dent. 2018;28(4):390-9.

41. Gilchrist F, Marshman Z, Deery C, Rodd HD. The impact of dental caries on children and young people: what they have to say? Int J Paediatr Dent. 2015;25(5):327-38.

42. Kaur P, Singh S, Mathur A, Makkar DK, Aggarwal VP, Batra M, Sharma A, Goyal N. Impact of dental disorders and its influence on self esteem levels among adolescents. J Clin Diagn Res. 2017;11(4):ZC05-8.

\section{Publisher's Note}

Springer Nature remains neutral with regard to jurisdictional claims in published maps and institutional affiliations.

Ready to submit your research? Choose BMC and benefit from:

- fast, convenient online submission

- thorough peer review by experienced researchers in your field

- rapid publication on acceptance

- support for research data, including large and complex data types

- gold Open Access which fosters wider collaboration and increased citations

- maximum visibility for your research: over $100 \mathrm{M}$ website views per year

At BMC, research is always in progress.

Learn more biomedcentral.com/submissions 